\title{
Deregulation of MUC4 in gastric adenocarcinoma: potential pathobiological implication in poorly differentiated non-signet ring
} cell type gastric cancer

\author{
S Senapati', P Chaturvedi', P Sharma ${ }^{2}$, G Venkatraman', JL Meza ${ }^{3}$, W El-Rifai ${ }^{4}$, HK Roy ${ }^{5}$ and SK Batra ${ }^{*}, 1,3$ \\ 'Department of Biochemistry and Molecular Biology, University of Nebraska Medical Center, Omaha, NE 68198, USA; ${ }^{2}$ Department of Pathology, \\ Creighton University Medical Center, Omaha, NE 681 31 , USA; ${ }^{3}$ Department of preventive and Societal Medicine, University of Nebraska Medical Center, \\ Omaha, NE 68198, USA; ${ }^{4}$ Department of Surgery, Vanderbilt University Medical Center, Nashville, Tennessee 37232, USA; ${ }^{5}$ Northwestern University \\ Feinberg School of Medicine, Division of Gastroenterology, Evanston Northwestern Healthcare, Evanston, IL 6020I, USA
}

MUC4 is a large, heavily glycosylated transmembrane mucin, that is implicated in the pathogenesis of various types of cancers. To date, no extensive study has been done to check the expression and functional significance of MUC4 in different types of gastric adenocarcinomas. Here, we report the expression profile of MUC4 in gastric adenocarcinomas and its function in poorly differentiated gastric non-signet ring cell carcinoma (non-SRCC) type cells. Immunohistochemical analysis using tissue microarray (TMA) showed a significant difference in MUC4 expression between normal adjacent $(n=45)$ and gastric adenocarcinoma $(n=83$; $P<0.00$ I). MUC4 expression was not associated with tumour type, stage or with the degree of differentiation. To gain further insight into the significance of MUC4 expression in gastric non-SRCC cells, MUC4 was ectopically expressed in AGS, a poorly differentiated gastric non-signet ring cell line. The MUC4 overexpressing cells (AGS-MUC4) showed a significant increase $(P<0.005)$ in cell motility and a decrease in cellular aggregation as compared with the vector-transfected cells. Furthermore, in vivo tumorigenicity analysis revealed that animals transplanted with the MUC4 overexpressing cells (AGS-MUC4) had a greater incidence of tumours (83\%) in comparison to empty vector control (I7\%). In addition, the expression of MUC4 resulted in enhanced expression of total cellular ErbB2 and phosphorylated ErbB2. In conclusion, our results showed that MUC4 is overexpressed in gastric adenocarcinoma tissues, and that it has a role in promoting aggressive properties in poorly differentiated gastric non-SRCC cells through the activation of the ErbB2 oncoprotein.

British Journal of Cancer (2008) 99, 949-956. doi:I 0.I038/sj.bjc.6604632 www.bjcancer.com (c) 2008 Cancer Research UK

Keywords: MUC4; mucin; gastric adenocarcinoma; signet ring cell carcinoma

Gastric cancer is the fourth most commonly found cancer worldwide and more than $90 \%$ of gastric cancers are adenocarcinomas (Correa et al, 2004). According to recent statistical information, in the United States, 21500 new gastric cancer cases are estimated for the year 2008 (Jemal et al, 2008). Despite advances in diagnostic techniques such as imaging, esophagogastroduodenoscopy, magnetic resonance imaging and dual-phase spiral computer tomography, early diagnosis of gastric adenocarcinoma is still a diagnostic problem for clinicians. An early detection with accurate diagnosis and effective surgical or endoscopic treatment can result in a better prognosis.

Gastric adenocarcinoma is classified into intestinal and diffuse type of adenocarcinomas (Lauren, 1965). Morphologically, the intestinal-type gastric adenocarcinoma has well-defined glands

\footnotetext{
* Correspondence: Professor SK Batra, Department of Biochemistry and Molecular Biology, Eppley Institute for Research in Cancer and Allied Diseases, University of Nebraska Medical Center, 985870 Nebraska Medical Center, Omaha, NE 68198-5870, USA;

E-mail: sbatra@unmc.edu

Received 9 June 2008; revised 31 July 2008; accepted 4 August 2008
}

with epithelial lining and diffuse-type gastric adenocarcinoma, which mainly consists of scattered individual cells or clusters of cells. It has been shown that the prevalence of poorly differentiated gastric carcinomas is higher than well differentiated gastric cancers (Nakamura et al, 1999).

Deregulation of mucins has been shown to be critical in a number of gastro-intestinal malignancies including gastric cancer. Normal gastric epithelial cells express a variety of mucins and have different functions, such as protection against mechanical and infectious insults, lubrication and acid resistance (Tasman-Jones, 1985; Hollingsworth and Swanson, 2004). Various reports have shown that altered mucin carbohydrate and peptide residues of mucins may be used as molecular markers of an increased risk of malignant transformation (Girling et al, 1989; Hakomori, 1989; Merlo et al, 1989; Ho et al, 1993; Springer et al, 1995; Llinares et al, 2004). Recent studies have provided strong evidences, which potentiate the role of mucins in the pathogenesis of various malignancies (Li et al, 2003; Yin et al, 2003; Singh et al, 2004). In gastric adenocarcinoma, mucin expression pattern is heterogeneous. Mucins in gastric carcinoma include normal mucins of stomach like MUC1, MUC5AC, MUC6 and de novo expression of the intestinal mucins MUC2 (Carrato et al, 1994; Ho et al, 1995; 
Sakamoto et al, 1997; Baldus et al, 1998; Reis et al, 1998, 2000; Utsunomiya et al, 1998).

MUC4, is a membrane-bound mucin and has a significant role in different cancers including pancreatic and breast cancers (Singh et al, 2004). MUC4 expression is also associated with the poor prognosis for pancreatic, lung and bile duct cancer patients. Overexpression of MUC4 in pancreatic cancer potentiates pancreatic tumour cell proliferation, survival and invasive properties and also interferes with its interaction to extracellular matrix proteins (Chaturvedi et al, 2007). MUC4 also interacts with ErbB2, a growth factor receptor, stabilizes it at the cell surface and hence has an important function in modulating ErbB2-mediated oncogenic signaling in pancreatic cancer cells (Chaturvedi et al, 2008). The importance of MUC4 for activation of ErbB2 in poorly differentiated gastric SRCC has been reported (Yokoyama et al, 2007). However, to date there is a lack of knowledge about the functional significance of MUC4 in poorly differentiated gastric cancers other than the SRCC subtypes.

Realizing the importance of MUC4 in different malignancies, we prompted to investigate the expression pattern of MUC4 in different gastric adenocarcinomas. In this study, we have shown that MUC4 is overexpressed in the gastric cancer and its expression pattern does not correlate with type, differentiation or stage of cancer. In consideration of MUC4 expression in poorly differentiated gastric non-SRCC cells and its role in the activation of ErbB2 in gastric SRCC cells, we did in vitro and in vivo studies to check the significance of MUC4 in non-SRCC cells. Here, we have shown that MUC4 overexpression in poorly differentiated AGS, gastric cancer cells, increases its aggressive cancer property in both in vitro and in vivo experiments. In addition, overexpression of MUC4 in AGS, gastric cancer cells, increases both total and phosphorylated form of ErbB2.

\section{MATERIALS AND METHODS}

\section{Cell culture and transfection}

AGS, MKN45 and KATOIII cell lines were obtained from the American Type Culture Collection (ATCC, Manassas, VA, USA). AGS cells were grown in Ham's F/12 supplemented with $10 \%$ fetal bovine serum, MKN45 cells were grown in RPMI-1640 supplemented with $10 \%$ fetal bovine serum and KATOIII cells were grown in RPMI-1640 supplemented with $20 \%$ fetal bovine serum. In all the media $100 \mathrm{~g} \mathrm{ml}^{-1}$ penicillin and streptomycin were added. Cell lines were maintained in a $37^{\circ} \mathrm{C}$ incubator with $5 \% \mathrm{CO}_{2}$ and in a humidified atmosphere. For the overexpression of MUC4 an engineered MUC4 construct (MUC4minigene) was made, which contains $10 \%$ of the tandem repeat sequence. The MUC4minigene construct was stably transfected in AGS cell line for constitutive expression of MUC4. For control, cells were transfected with empty vector (pSecTagC). Stable clones were then selected in a medium containing Zeocin $\left(400 \mathrm{mg} \mathrm{ml}^{-1}\right)$. The Zeocin-resistant colonies were isolated by the ring cloning method and maintained in the medium supplemented with Zeocin. The medium was replaced with a complete medium without antibiotic supplement for at least 5 days before any analysis.

\section{Immunoblot assay}

The AGS, MKN45 and KATOIII cell lines were processed for extraction of whole cell protein and using standard protocol western blotting was carried out. The cells were washed two times with phosphate-buffered saline (PBS) and scraped in radioimmunoprecipitation assay buffer $(50 \mathrm{~mm}$ Tris, $5 \mathrm{~mm}$ ethylenediaminetetraacetic acid (EDTA), $150 \mathrm{~mm} \mathrm{NaCl}, 0.25 \%$ sodium deoxycholate, $1 \% \mathrm{NP} 40 \mathrm{pH}$ 7.5), supplemented with protease inhibitor mixture (Roche Diagnostics, Mannheim, Germany) and kept at $4{ }^{\circ} \mathrm{C}$ for at least $30 \mathrm{~min}$. Cell lysates were passed through the $28 \mathrm{G}$ tuberculin needle or alternatively subjected to one freeze thaw cycle to facilitate the disruption of the cell membranes. Cell lysates were centrifuged at 14000 r.p.m. for $20 \mathrm{~min}$ at $4^{\circ} \mathrm{C}$ and supernatants were collected. Using a BIO-RAD DC protein estimation kit the samples were quantified. Owing to the large size of MUC4, the protein samples were resolved by electrophoresis on a $2 \%$ SDS-agarose gel under reducing condition. Resolved proteins were transferred onto the polyvinylidene difluorided membrane. For MUC4 detection anti-MUC4 mouse monoclonal antibody (8G7) was used. For the detection of total ErbB2/HER2 and phosphorylated ErbB2/HER2, anti-HER2 rabbit polyclonal (Santa Cruz Biotechnology, Santa Cruz, CA, USA) and pY1248-HER2 (Upstate Biotech, Lake Placid, NY, USA) antibodies were used respectively. Secondary antibodies consisted of horseradish peroxidase-conjugated anti-mouse/anti-rabbit, which were used for the immunodetection. The blots were processed with ECL chemiluminescence kit (Amersham Biosciences, Piscataway, NJ, USA), and the signal was detected by exposing the processed blots to X-ray films (Biomax Films, Kodak, NY, USA).

\section{Confocal immunofluorescence microscopy}

Cells were grown at low density on sterile coverslips for $20 \mathrm{~h}$. After washing with $0.1 \mathrm{~m}$ HEPES containing Hanks buffer, the cells were fixed in ice-cold methanol at $-20^{\circ} \mathrm{C}$ for $2 \mathrm{~min}$. Nonspecific blocking was done by using $10 \%$ goat serum containing $0.05 \%$ Tween-20 for $30 \mathrm{~min}$, followed by incubation with anti-MUC4 monoclonal antibody (8G7) in PBS for $90 \mathrm{~min}$ at room temperature. Cells were washed 3-4 times with PBS containing $0.05 \%$ Tween-20 (PBS-T) and then incubated with FITC-conjugated goat anti-mouse secondary antibodies for $60 \mathrm{~min}$. The cells were counterstained with propidium iodide. Finally slides were washed two times with PBS and mounted on glass slides in antifade Vectashield mounting medium (Vector Laboratories, Burlingame, CA, USA). The slides were observed under a ZEISS confocal laserscanning microscope, and photographs were captured digitally using 510 software.

\section{Tissue microarrays and immunohistochemistry}

To have more number of sample sizes, tissue microarray slides were ordered from two different companies. The AccuMax TM (cat. no. A209) has total of 50 different cancer cases and four nonneoplastic tissues (one corresponding, three non-corresponding). The TMA slide had two spots for each cancer tissue and one spot for each non-neoplastic tissue. Tissue microarray slide from US Biomax Inc. (ST801) had a total of 40 individual cases and each normal adjacent tissue is placed next to its matched cancer tissue. As per recommendations of the manufacturer, before conducting immunohistochemistry, the slides were baked at $60^{\circ} \mathrm{C}$ for $2 \mathrm{~h}$. Then slides were deparaffinized by using EzDewax (Bio Genex, CA, USA) for $30 \mathrm{~min}$. Sections were hydrated through graded alcohol and endogenous peroxidase activity was quenched by incubating the sections in $0.3 \% \mathrm{H}_{2} \mathrm{O}_{2}$ in methanol for $30 \mathrm{~min}$. After washing the slides in PBS ( 5 min $\times 2)$, antigen retrieval was done by heating the slides in citrate buffer $(0.01 \mathrm{M}, \mathrm{pH} 6.0)$ at $80^{\circ} \mathrm{C}$ for $20 \mathrm{~min}$. After heating the samples were allowed to cool for 15-20 min in room temperature. This was followed by washing with PBS $(5 \mathrm{~min} \times 2)$. Nonspecific binding was blocked by incubating the sections with $2.5 \%$ horse serum for $30 \mathrm{~min}$ (Impress reagent Kit,Vector).This was followed by washing with PBS $(5 \mathrm{~min} \times 2)$. Sections were then incubated with anti-MUC4 monoclonal antibody $(1: 2500)$ at $4{ }^{\circ} \mathrm{C}$ overnight. Then slides were washed and incubated with secondary antibody (peroxidase labeled Universal anti-mouse/anti-rabbit IgG (Vector, CA)) for $30 \mathrm{~min}$. Then sections were washed with PBS followed by treatment with $\mathrm{DAB}$ reagents $\left(0.2 \mathrm{mg} \mathrm{ml}^{-1}\right)$ and 
incubated for $10 \mathrm{~min}$. After washing with distilled water, counter staining was done by using haematoxylin (Vector, CA, USA). After washing in tap water, sections were dehydrated in graded alcohol and after air drying the slides were mounted in permount permanent mounting media (Fisher Scientific, Fair Lawn, NJ, USA). All slides were observed under Nikon E400 light microscope and representative photographs were taken.

\section{Motility assay}

For motility assay, $1 \times 10^{6}$ cells were plated on the top chamber of a non-coated polyethylene teraphthalate membrane (six-well inset, pore size $8 \mu \mathrm{m}$; Becton Dickinson, Franklin Lakes, NJ, USA). The bottom chamber contained $1.0 \mathrm{ml}$ DMEM supplemented with $10 \%$ fetal bovine serum. The cells were incubated for $24 \mathrm{~h}$, and the cells that did not migrate through the pores in the membrane were removed by scraping the membrane with a cotton swab. Cells that transversed the membrane were stained with Diff-Quick cell staining kit (Dade Behring Inc., Newark, DE, USA). Cells in 10 random fields of view at $\times 100$ magnifications were counted and expressed as the average number of cells/field of view. Three independent experiments were done in each case. These data were represented as the average of the three independent experiments with the s.d. of the average indicated.

\section{Aggregation assay}

Cells were tested for their ability to aggregate in hanging drop suspension cultures. Cells were trypsinized in the presence of EDTA, washed two times in PBS, and resuspended at $2.5 \times 10^{5}$ cells $\mathrm{ml}^{-1}$ in the appropriate medium containing $10 \%$ fetal bovine serum. Drops ( $20 \mu \mathrm{l}$ each) of medium, containing 5000 cells/drop, were pipetted onto the inner surface of the lid of a Petri dish. The lid was then placed on the Petri dish so that the drops were hanging from the lid with the cells suspended within them. To eliminate evaporation, $8 \mathrm{ml}$ of serum-free culture medium were placed in the bottom of the Petri dish. After overnight incubation at $37^{\circ} \mathrm{C}$, the lid of the Petri dish was inverted and photographed using a Nikon TS100 inverted tissue culture microscope at $\times 40$ magnifications.

\section{In vivo tumorigenicity assay}

To test the tumorigenic capacity, the MUC4-transfected AGS cells along with the control cells were harvested from subconfluent cultures by a brief exposure to $0.25 \%$ trypsin and $0.02 \%$ EDTA. After neutralising the effect of trypsin with $10 \%$ fetal bovine serum, the cells were washed once in PBS. Cell viability and number were determined by trypan blue staining using a hemocytometer. Cells were resuspended in a normal saline solution at a concentration of $25 \times 10^{6}$ cells ml $^{-1}$. Single-cell suspensions of $>90 \%$ viability was used for the injections. Immunodeficient mice were purchased from the Animal Production Area of the National Cancer Institute-Frederick Cancer Research and Development Center (Frederick, MD, USA). The mice were housed in specific pathogen-free conditions and fed sterile water and food ad libitum. The mice were treated in accordance with the Institutional Animal Care and Use Committee guidelines. $5 \times 10^{6}$ viable MUC4-transfected AGSMUC4 cells, resuspended in a normal saline solution, were injected subcutaneously in six immunodeficient mice. Empty vector transfected cells (AGS-pSecTagC) were used as a control $(n=6)$. The animals were monitored two times weekly for tumour formation up to 4 months after inoculation. A palpable mass was observed at the inoculation site at around 80 days of postinjection, followed by rapid growth of the tumour. All mice were killed on day 120 after implantation, and the incidence of tumour was determined.

\section{Statistical analysis}

Subjects with normal or adenocarcinoma or signet ring cell carcinoma were included in the analysis. The distribution of type, grade and stage was compared between positive and negative intensity groups using a $\chi^{2}$ test or Fisher's Exact test where appropriate. Tumour incidence was compared between groups using Fisher's Exact test.

\section{RESULTS}

\section{Immunohistochemical analysis of MUC4 expression in gastric cancer tissues}

As a first step toward studying the role of MUC4 in gastric cancer, we did immunohistochemical analysis of MUC4 expression on TMA samples of gastric adenocarcinoma and normal adjacent area. MUC4 staining showed a diffuse staining pattern (membrane/ cytoplasmic) in most of the tissue sections. Representative pictures of the stained gastric tumour tissue sections are presented in Figure 1. Statistical analysis was conducted to determine the association of MUC4 expression pattern with cancer type, differentiation and stage of the tumour (Tables 1 and 2). Out of a total of 128 tissue spots, we found that the proportion of MUC4positive staining is lower for normal adjacent spots $(n=45,9 \%)$ compared with patients with adenocarcinoma $(n=58,43 \%)$ and signet ring cell carcinoma $(n=25,32 \%)(P<0.001)$. However, no significant difference was found in MUC4 expression between adenocarcinomas and signet ring cell carcinomas $(P=0.34)$. Furthermore, no significant correlation was found between tumour differentiation and MUC4 expression for all cancer patients combined $(P=0.34)$ (Table 1$)$. MUC4 expression pattern did not significantly correlate with the stage of tumour, both individually $(P=0.16)$ or in groups, that is, I/II (early stage) and III/IV (late stage) $(P=0.21)$ (Table 2$)$.

\section{Expression of MUC4 in different gastric cancer cell lines}

Using immunoblot assay, MUC4 expression was checked in three different types of gastric adenocarcinoma cell lines (AGS, MKN45 and KATOIII). MUC4 expression was detected in KATOIII (SRCC) but was undetectable in AGS and MKN45 cell lines (Figure 2). To further analyse the role of MUC4 in the aggressiveness of nonsignet ring cell type poorly differentiated gastric adenocarcinomas, MUC4 was ectopically expressed in AGS gastric cancer cell line (using an engineered MUC4 cDNA construct, MUC4minigene (Moniaux et al, 2007)). The MUC4minigene's deduced protein $(320 \mathrm{kDa})$ is analogous to that of wild-type MUC4 protein $(930 \mathrm{kDa})$ (Moniaux et al, 2007). Western blot analysis (Figure 3) and confocal study showed the overexpression of MUC4 in selected clones transfected with MUC4 construct in comparison to empty vector transfected clones (Figure 3). Furthermore, confocal analysis showed the membrane localisation of MUC4 in AGSMUC4 clones.

\section{MUC4 overexpression increases cell motility in AGS gastric cancer cells}

The aggressiveness of a malignant cell depends on its potential to invade the ECM and its ability to metastasize to distant sites. Different studies have shown that the invasive and metastasis potential of cancer cells are strongly related to a variety of phenotypic characteristics. Among these characteristics, motility of cells highly influences the metastatic property of cells (Yamaguchi et al, 2005). As the MUC4 overexpression is associated with an increased motility of pancreatic cancer cells, we examined whether the MUC4 overexpression in gastric cancer is associated with an increase in cell motility or not. Cell motility was 

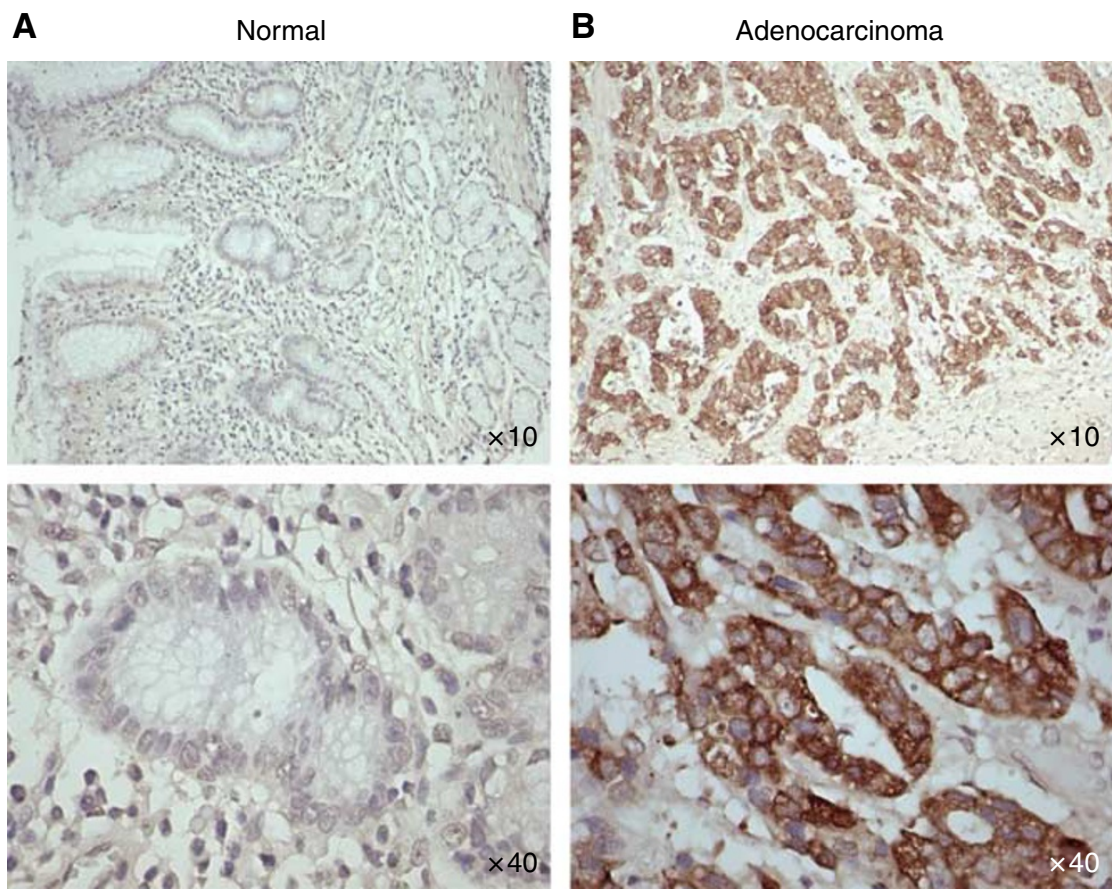

Figure I Immunohistochemical analysis of gastric tissues for MUC4 expression by using gastric cancer tissue microarray (TMA) slides. Tissue sections were stained for MUC4 using anti-MUC4 monoclonal antibody followed by biotinylated secondary antibody incubation and streptavidin peroxidase 3,3'diaminobenzidine-chromogen detection. All the sections were examined under microscope and the immunoreactivity was judged by dark brown staining. (A) Representative picture of stained gastric normal adjacent tissues showing no visible MUC4 staining. (B) Representative picture of gastric adenocarcinoma tissues showing diffused MUC4 staining. All sections were counter stained with haematoxylin. In all the top panels, original magnification is $\times 10$ and in bottom panels, original magnification is $\times 40$.

Table I Association of MUC4 expression pattern with types and grades of gastric cancer

\begin{tabular}{lccc}
\hline & $\begin{array}{c}\text { MUC4-negative } \\
\text { N (\%) }\end{array}$ & $\begin{array}{c}\text { MUC4-positive } \\
\text { N (\%) }\end{array}$ & P-value \\
\hline Types & & & \\
$\quad$ Normal & $41(91 \%)$ & $4(9 \%)$ & $P<0.001$ \\
Adenocarcinoma & $33(57 \%)$ & $25(43 \%)$ & \\
SRCC & $17(68 \%)$ & $8(32 \%)$ & \\
& & & \\
Differentiation & & $8(47 \%)$ & \\
Moderate & $9(53 \%)$ & $22(42 \%)$ & $P=0.34$ \\
Poor & $30(58 \%)$ & $0(0 \%)$ & \\
Not & $4(100 \%)$ & $3(30 \%)$ & \\
Well & $7(70 \%)$ & & \\
\hline
\end{tabular}

determined on top of the uncoated porous membrane. The number of MUC4 overexpressing AGS gastric cancer cells (AGS-MUC4) migrated to the lower surface of the porous membrane was significantly high $(P<0.005)$ than that of the vector control (AGSvector) cells (Figure $4 \mathrm{~A})$.

\section{Overexpression of MUC4 decreases aggregation property of AGS gastric cancer cells}

Like cell motility, aggregation property of cells is also a critical factor, which affects the metastasis property of tumour cells. The aggregation property is usually deregulated in the tumour cells because of alteration in the expression of different cell surface molecules (Sommers, 1996; Komatsu et al, 1997; Truant et al, 2003). Therefore, to test the effect of MUC4 overexpression on adhesiveness of AGS cells, we used the
Table 2 Association of MUC4 expression pattern with stages of gastric cancer

\begin{tabular}{lccc}
\hline Cancer stage & $\begin{array}{c}\text { MUC4-negative } \\
\mathbf{N}=\mathbf{2 8}\end{array}$ & $\begin{array}{c}\text { MUC4-positive } \\
\mathbf{N}=\mathbf{I 9}\end{array}$ & $\boldsymbol{P}$-value \\
\hline I & II $(58 \%)$ & $8(42 \%)$ & $0.16 * * *$ \\
II & $6(100 \%)$ & $0(0 \%)$ & \\
III & $9(50 \%)$ & $9(50 \%)$ & \\
IV & $2(50 \%)$ & $2(50 \%)$ & \\
\hline
\end{tabular}

***Fisher's Exact test. Information regarding the tumour stage was not available for all the spots.

aggregation assay described in Materials and methods. MUC4 overexpression showed a decrease in aggregation of AGS-MUC4transfected cells in comparison to vector-transfected control cells (Figure 4B).

\section{Overexpression of MUC4 enhances tumorigenicity of AGS gastric cancer cells in nude mice}

To investigate the role of MUC4 on tumorigenic property of gastric cancer cells, AGS-MUC4 and AGS-vector cells, were injected subcutaneously into immune deficient nude mice. $5 \times 10^{6}$ cells were injected and a palpable mass was first noticed at the eightieth day of post-inoculation and continued to grow up to 120 days. Among the six mice inoculated with AGS-MUC4 cells, incidence of tumour was observed in five mice $(83 \%)$, whereas only one mouse had a tumour among the six mice inoculated with AGS-vector cells $(17 \%)$. Further, statistical analysis showed that this difference in the incidence of the tumour between the two groups is marginally significant $(P=0.08)$ (Table 3$)$. 


\section{Overexpression of MUC4 activates ErbB2 oncoprotein in AGS gastric cancer cells}

shRNA-mediated knock-down of MUC4 in pancreatic cancer cells showed a decrease in the total levels and phosphorylated form of ErbB2 protein (at $\mathrm{Tyr}^{1248}$ ) and was shown that overexpression of MUC4 plays a crucial role in stabilising ErbB2 (Chaturvedi et al, 2007, 2008). Other studies have shown that in SRCC type gastric cancer cells, MUC4 is required for the activation of ErbB2 (Yokoyama et al, 2007). On the basis of these earlier observations, we wanted to determine whether MUC4 exerts its function through regulating ErbB2 expression and activation in AGS-MUC4 gastric cancer cells. The expression of total and active form of ErbB2 was measured by western blot analysis. Cell lysate of AGS-MUC4 showed increased level of total and phosphorylated (at $\mathrm{Tyr}^{1248}$ ) ErbB2 protein compared with the control AGS-vector cell lysate (Figure 5).

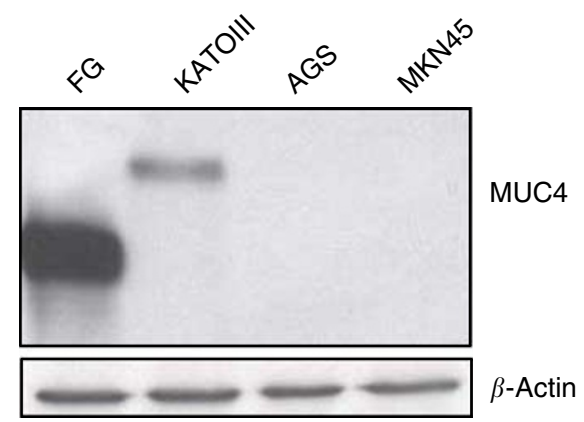

Figure 2 Western blot analysis of MUC4 expression in gastric cancer cell lines. Total protein lysates from AGS, KATOIII and MKN45 gastric cancer cells were prepared. Protein lysate from FG (pancreatic cancer cell line) cells was taken as a positive control. Protein lysates were electrophoretically resolved on $2 \%$ agarose gel. Resolved proteins were transferred onto PVDF membrane and probed with MUC4 MAb (8G7) and detected using Amersham HRP-conjugated secondary antibody and ECL kit. Immunoblot of $\beta$-actin, obtained from 10\% SDS-PAGE/ Western, was used as an internal control to correct for the loading variation.

\section{DISCUSSION}

MUC4 is one of the most widely studied membrane-bound mucins having a significant function in the pathogenesis of several cancers (Shibahara et al, 2004; Singh et al, 2004). The aberrant expression of MUC4 has been reported in different types of carcinomas (Andrianifahanana et al, 2001; Llinares et al, 2004; Weed et al, 2004). It has been shown that MUC4 expression correlates with cancer progression (Swartz et al, 2002; Park et al, 2003). In this study, we showed that MUC4 is overexpressed in gastric cancer tissues as compared with normal adjacent tissues. Overexpression of MUC4 was associated with an aggressive phenotype of gastric cancer cells. MUC4 overexpression also increased the activation of ErbB2 oncoprotein. Hence, our study provides for the first time, the importance of MUC4 in gastric cancer and explains the possible mechanism through which MUC4 can promote aggressive property of poorly differentiated gastric non-SRCC cells.

In this study, we examined and compared the expression of MUC4 in gastric cancer tissues. MUC4 showed a significant overexpression in gastric cancer tissues compared with the normal adjacent tissues. Similar findings showing the overexpression of MUC4 in gastric adenocarcinoma has been reported earlier (Lopez-Ferrer et al, 2000). MUC4 is known to be expressed in the embryonic gastric tissues around 8 weeks of gestation (Buisine et al, 2000). It has also been shown that many embryogenesis phenomena like cell proliferation, lineage allocation, cell migration and differentiation of cells are also seen during cancer progression. Therefore, overexpression of MUC4 in adult gastric carcinoma supports the concept of 'fetal antigen' expression during malignant condition and indicates its possible role in gastric cancer progression. Further, our statistical analysis showed that there is no significant association between MUC4 expression with type, grade of differentiation and stage of gastric cancer. This suggests that MUC4 itself may not be a potential marker for early diagnosis of gastric cancer. Previous studies performed regarding the role of mucins as diagnostic and prognosis markers in gastric carcinoma tissue showed contradictory results (Correa and Shiao, 1994; Byrd et al, 1997). Therefore, for higher accuracy, many studies have been done to evaluate the combined expression pattern of mucins with other molecules such as E-cadherin with MUC1 expression (Tanaka et al, 2003). Similarly, comparing the expression pattern
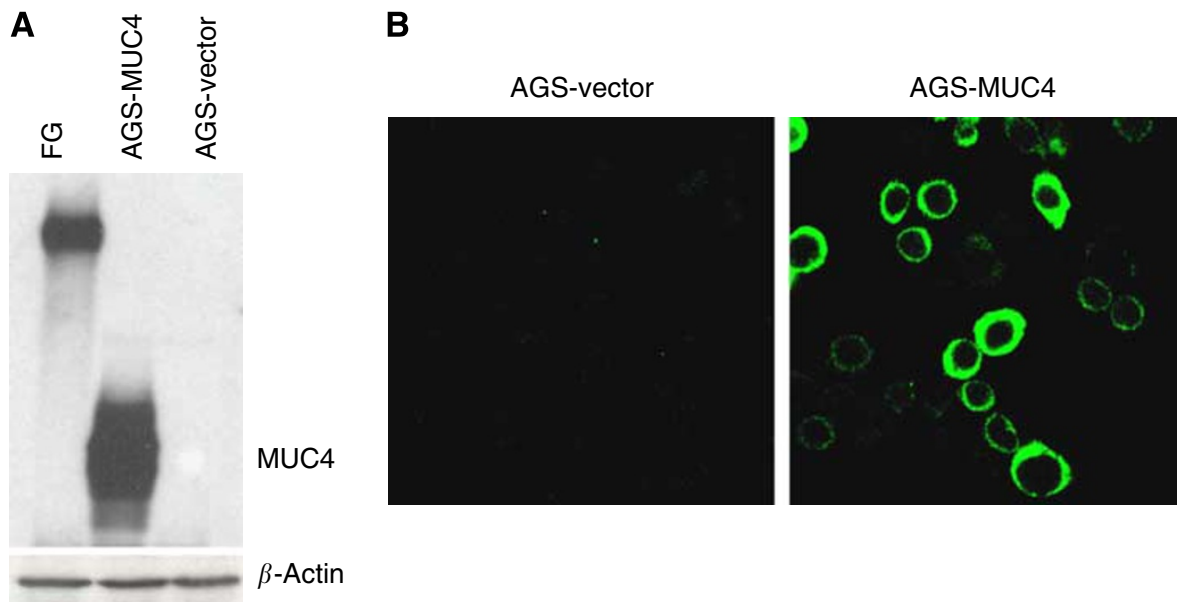

Figure 3 Expression of MUC4 in AGS and its derived sublines: AGS-vector (empty vector transfected) and AGS-MUC4 (MUC4-transfected) cells. (A) Western blot analysis: total protein lysates were prepared from the subconfluent cells. A total of $20 \mu \mathrm{g}$ protein from cell extracts was electrophoretically resolved on 2\% Agarose gel. Resolved proteins were transferred onto PVDF membrane and probed with MUC4 MAb (8G7). Protein from FG (pancreatic cancer cell line) cells was taken as a positive control. (B) Expression analysis of MUC4 using confocal microscopy: Cells were grown at a low density on sterilised cover slips; after methanol fixation, slides were incubated with MUC4 MAb (8G7), followed by FITC-conjugated secondary antibody, and were observed under a ZEISS confocal laser-scanning microscope (magnification, $\times$ 630). 
A

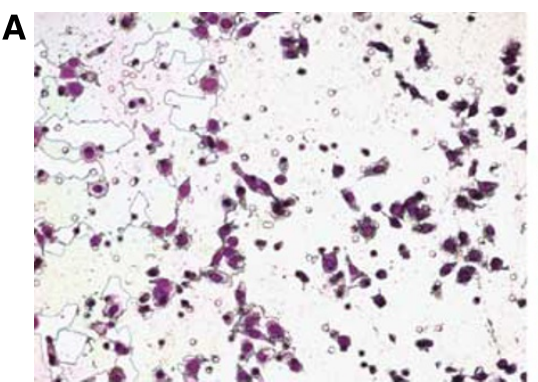

AGS-vector

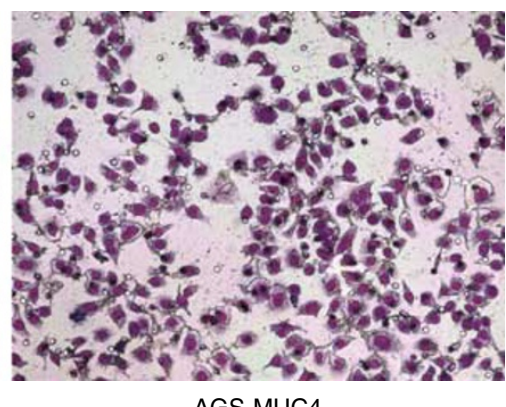

AGS-MUC4

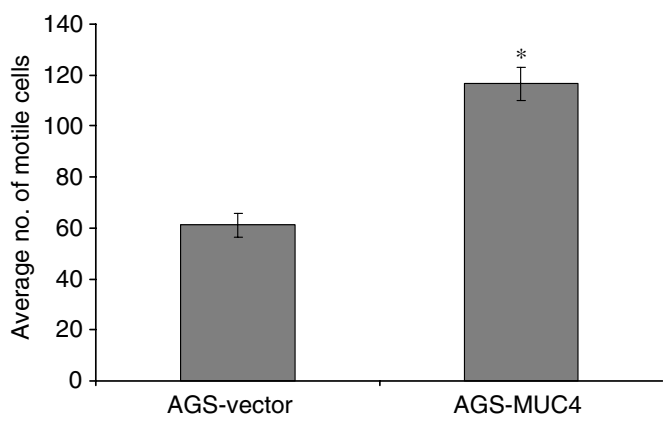

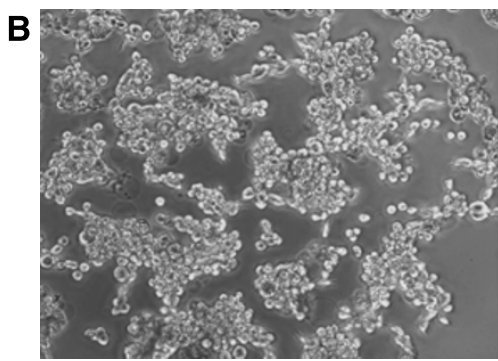

AGS-vector

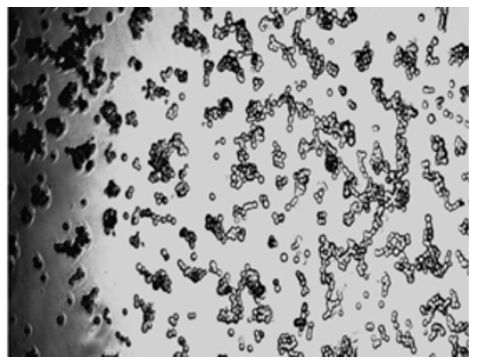

AGS-MUC4

Figure 4 Phenotypic changes of AGS-MUC4 cells compared with AGS-vector cells. (A) Cell motility assay: MUC4 expression correlates with the cell motility. Cells $\left(I \times 10^{6}\right)$ were plated in the top chamber of noncoated polyethylene teraphthalate membranes and incubated for $20 \mathrm{~h}$. Cells that transversed the membranes were stained with a Diff-Quick cell staining kit. The number of cells transversing the membrane was determined by averaging 10 random fields of view at $\times 100$ and expressed as the average number of cells/field of view and is the average of two independent experiments. Mean \pm s.e.; $n=20$ ${ }^{*} P<0.005$. Cell motility was significantly $(P<0.005)$ increased in MUC4-transfected AGS cells. (B) Aggregation assay: drops of medium (20 $\mu$ l each) containing 500 cells/drop were pipetted onto the inner surface of the lid of a Petri dish. After overnight incubation at $37^{\circ} \mathrm{C}$, the lid of the Petri dish was inverted and photographed using a Nikon TSI00 inverted tissue culture microscope at $\times 40$ magnification. An increased cellular aggregation observed in AGS-MUC4 cells.

Table 3 Incidence of tumours in animals injected with AGS-MUC4 and AGS-pSecTagC cells

\begin{tabular}{lccc}
$\begin{array}{l}\text { Name of the } \\
\text { group }\end{array}$ & $\begin{array}{c}\text { Number of } \\
\text { animals injected }\end{array}$ & $\begin{array}{c}\text { Number of animals } \\
\text { having tumour }\end{array}$ & P-value \\
\hline AGS-MUC4 & 6 & $5(83 \%)$ & $P=0.08^{* * * * *}$ \\
AGS-Vector & 6 & $1(17 \%)$ & \\
\hline
\end{tabular}

***** Fisher's Exact test

of MUC4 with other proteins like E-cadherin or other mucins will strengthen the study and may potentiate the possible use of MUC4 as a diagnostic and prognostic marker for gastric adenocarcinomas.

Different studies have shown the functional role of MUC4 in tumorigenicity and metastasis property of cancer cells (Singh et al, 2004; Chaturvedi et al, 2007). Recently, we have also shown that in pancreatic cancer cells MUC4 interacts with ErbB2 and stabilizes its localization on the cell membrane (Chaturvedi et al, 2008). In another very recent study, it has been shown that MUC4 interacts with ErbB2 in human gallbladder carcinoma and helps in the activation of erbB2 (Miyahara et al, 2008).Till date, information regarding the role of MUC4 in gastric cancer is very less, recently, it has been shown that specifically in poorly differentiated type gastric signet ring cell carcinoma cells, MUC4 is required for the activation of ErbB2. Because MUC4 is expressed even in poorly differentiated gastric non-SRCC cells, we therefore reasoned that MUC4 might have a possible role in those kinds of cells. Here, we report that out of the three poorly differentiated cells (KATOIII, MKN45 and AGS), only KATOIII, which is a signet ring cell carcinoma cell line, expresses MUC4.

Further, to check the actual role of MUC4 in non-SRCC type poorly differentiated gastric cancer cells, MUC4 was ectopically

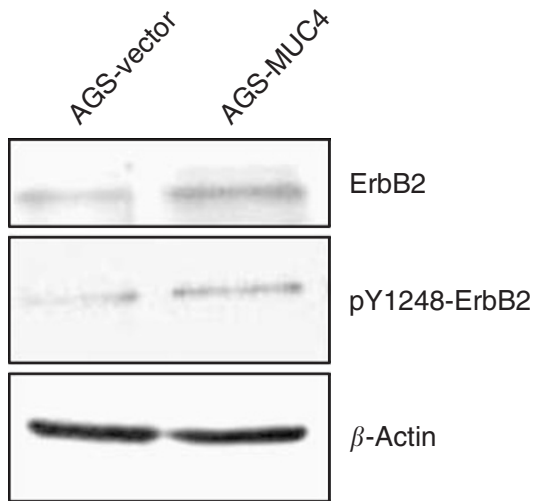

Figure 5 Effect of MUC4 expression on ErbB2 expression and phosphorylation. (A) Western blot analysis: a total of $20 \mu \mathrm{g}$ of protein from AGS-derived cell lines, were resolved by SDS-PAGE and transferred to PVDF membrane and probed with antibodies against, ErbB2, Phosphotyr 1248 ErbB2, and $\beta$-actin. MUC4-transfected AGS cells showed an increased level of total and phosphorylated ErbB2 in comparison to vectortransfected cells.

overexpressed in a gastric adenocarcinoma cell line (AGS), which has an undetectable expression level of MUC4. In different in vitro studies, we found that, MUC4 causes an increase in the motility of AGS-MUC4 cells, and a decrease in the adhesive property of AGSMUC4 cells. This finding supports other studies where MUC4 has a similar function in other cancers, such as pancreatic cancer (Singh et al, 2004; Chaturvedi et al, 2007). The increase in cell motility $(P<0.05)$, which has a major role during the dynamic process of tumour invasion and metastasis, may be a direct result of 
MUC4-mediated changes in the actin organisation, or indirectly through an ErbB2-mediated pathway (Singh et al, 2007). During cancer cell metastasis, cells remain loosely attached to the ECM or to the other cells. This property is essential to make the cells more migratory and to increase the invasiveness of cancer cells. In our aggregation assay, we found that MUC4 overexpression in AGS cell line, decreases its aggregation property, or in other words enhances its metastatic property. This decreased adhesive property among cells may be because of charge-charge repulsion on account of the presence of negatively charged O-glycosidic chains present in the central repetitive domain of MUC4 or owing to disruption of integrin-mediated cell adhesion. Furthermore, the high incidence of tumours in animals injected with AGS-MUC4 cells than animals inoculated with AGS-vector cells, indicate the role of MUC4 in tumorigenicity of gastric cancer cells.

Decrease in cell death and increase in cell proliferation are two major regulatory elements in enhancing the tumorigenicity of cancer cells. Overexpression of ErbB2 oncoprotein has been shown to correlate with tumour aggressiveness in various tumours (Hynes and Lane, 2005). In gastric cancer, a correlation between ErbB2 gene amplification and prognosis of patients has been reported (Nakajima et al, 1999; Lin et al, 2000). In this study, similar to our previous report, we also observed an increase in total ErbB2 and phosphorylated ErbB2 expression in MUC4 expressing AGS cells. AGS, is a well studied poorly differentiated cell line (Barranco et al,
1983). The tumorigenicity of this cell line in animals has been already reported (Barranco et al, 1983). Here, the increase in tumorigenicity of AGS cells mediated by MUC4 may be on account of the interaction of MUC4 with ErbB2 and further stabilisation and activation of ErbB2-mediated oncogenic signaling.

In conclusion, our in vitro and in vivo studies showed a significant role of MUC4 in promoting the aggressiveness and tumorigenicity of poorly differentiated gastric non-SRCC cells. In addition, we showed a possible mechanism through which MUC4 can increase the tumorigenicity property of poorly differentiated gastric non-SRCC cells. Validation for MUC4 expression as a prognostic marker requires further studies. A study on the combined expression pattern of MUC4 and other molecules like E-cadherin or other mucins may provide more accuracy and specificity to use MUC4 as a diagnostic or prognostic marker for gastric cancer. Our study also indicates that MUC4 can be targeted for treatment of gastric cancer.

\section{ACKNOWLEDGEMENTS}

This work was supported by grants from the National Institutes of Health (CA78590, CA111294). We thank Ms Kristi L Berger for editing the paper. The invaluable technical support of Mr Erik Moore was greatly appreciated.

\section{REFERENCES}

Andrianifahanana M, Moniaux N, Schmied BM, Ringel J, Friess H, Hollingsworth MA, Buchler MW, Aubert JP, Batra SK (2001) Mucin (MUC) gene expression in human pancreatic adenocarcinoma and chronic pancreatitis: a potential role of MUC4 as a tumor marker of diagnostic significance. Clin Cancer Res 7: 4033-4040

Baldus SE, Zirbes TK, Engel S, Hanisch FG, Monig SP, Lorenzen J, Glossmann J, Fromm S, Thiele J, Pichlmaier H, Dienes HP (1998) Correlation of the immunohistochemical reactivity of mucin peptide cores MUC1 and MUC2 with the histopathological subtype and prognosis of gastric carcinomas. Int J Cancer 79: 133-138

Barranco SC, Townsend Jr CM, Casartelli C, Macik BG, Burger NL, Boerwinkle WR, Gourley WK (1983) Establishment and characterization of an in vitro model system for human adenocarcinoma of the stomach. Cancer Res 43: $1703-1709$

Buisine MP, Devisme L, Maunoury V, Deschodt E, Gosselin B, Copin MC, Aubert JP, Porchet N (2000) Developmental mucin gene expression in the gastroduodenal tract and accessory digestive glands. I. Stomach. A relationship to gastric carcinoma. J Histochem Cytochem 48: $1657-1666$

Byrd JC, Yan P, Sternberg L, Yunker CK, Scheiman JM, Bresalier RS (1997) Aberrant expression of gland-type gastric mucin in the surface epithelium of Helicobacter pylori-infected patients. Gastroenterology 113: $455-464$

Carrato C, Balague C, De BC, Gonzalez E, Gambus G, Planas J, Perini JM, Andreu D, Real FX (1994) Differential apomucin expression in normal and neoplastic human gastrointestinal tissues. Gastroenterology 107: $160-172$

Chaturvedi P, Singh AP, Chakraborty S, Chauhan SC, Bafna S, Meza JL, Singh PK, Hollingsworth MA, Mehta PP, Batra SK (2008) MUC4 mucin interacts with and stabilizes the HER2 oncoprotein in human pancreatic cancer cells. Cancer Res 68: 2065-2070

Chaturvedi P, Singh AP, Moniaux N, Senapati S, Chakraborty S, Meza JL, Batra SK (2007) MUC4 mucin potentiates pancreatic tumor cell proliferation, survival, and invasive properties and interferes with its interaction to extracellular matrix proteins. Mol Cancer Res 5: 309-320

Correa P, Shiao YH (1994) Phenotypic and genotypic events in gastric carcinogenesis. Cancer Res 54: 1941s-1943s

Correa P, Piazuelo MB, Camargo MC (2004) The future of gastric cancer prevention. Gastric Cancer 7: 9-16

Girling A, Bartkova J, Burchell J, Gendler S, Gillett C, Taylor-Papadimitriou J (1989) A core protein epitope of the polymorphic epithelial mucin detected by the monoclonal antibody SM-3 is selectively exposed in a range of primary carcinomas. Int J Cancer 43: 1072-1076
Hakomori S (1989) Aberrant glycosylation in tumors and tumor-associated carbohydrate antigens. Adv Cancer Res 52: 257-331

Ho SB, Niehans GA, Lyftogt C, Yan PS, Cherwitz DL, Gum ET, Dahiya R, Kim YS (1993) Heterogeneity of mucin gene expression in normal and neoplastic tissues. Cancer Res 53: 641-651

Ho SB, Shekels LL, Toribara NW, Kim YS, Lyftogt C, Cherwitz DL, Niehans GA (1995) Mucin gene expression in normal, preneoplastic, and neoplastic human gastric epithelium. Cancer Res 55: $2681-2690$

Hollingsworth MA, Swanson BJ (2004) Mucins in cancer: protection and control of the cell surface. Nat Rev Cancer 4: 45-60

Hynes NE, Lane HA (2005) ERBB receptors and cancer: the complexity of targeted inhibitors. Nat Rev Cancer 5: $341-354$

Jemal A, Siegel R, Ward E, Hao Y, Xu J, Murray T, Thun MJ (2008) Cancer statistics, 2008. CA Cancer J Clin 58: 71-96

Komatsu M, Carraway CA, Fregien NL, Carraway KL (1997) Reversible disruption of cell-matrix and cell-cell interactions by overexpression of sialomucin complex. J Biol Chem 272: 33245-33254

Lauren P (1965) The two histological main types of gastric carcinoma: diffuse and so-called intestinal-type carcinoma. an attempt at a histoclinical classification. Acta Pathol Microbiol Scand 64: $31-49$

Li Y, Liu D, Chen D, Kharbanda S, Kufe D (2003) Human DF3/MUC1 carcinoma-associated protein functions as an oncogene. Oncogene 22: $6107-6110$

Lin W, Kao HW, Robinson D, Kung HJ, Wu CW, Chen HC (2000) Tyrosine kinases and gastric cancer. Oncogene 19: 5680-5689

Llinares K, Escande F, Aubert S, Buisine MP, De BC, Batra SK, Gosselin B, Aubert JP, Porchet N, Copin MC (2004) Diagnostic value of MUC4 immunostaining in distinguishing epithelial mesothelioma and lung adenocarcinoma. Mod Pathol 17: 150-157

Lopez-Ferrer A, De BC, Barranco C, Garrido M, Isern J, Carlstedt I, Reis CA, Torrado J, Real FX (2000) Role of fucosyltransferases in the association between apomucin and Lewis antigen expression in normal and malignant gastric epithelium. Gut 47: 349-356

Merlo GR, Siddiqui J, Cropp CS, Liscia DS, Lidereau R, Callahan R, Kufe DW (1989) Frequent alteration of the DF3 tumor-associated antigen gene in primary human breast carcinomas. Cancer Res 49: 6966-6971

Miyahara N, Shoda J, Ishige K, Kawamoto T, Ueda T, Taki R, Ohkohchi N, Hyodo I, Thomas MB, Krishnamurthy S, Carraway KL, Irimura T (2008) MUC4 interacts with ErbB2 in human gallbladder carcinoma: potential pathobiological implications. Eur J Cancer 44: 1048-1056

Moniaux N, Chaturvedi P, Varshney GC, Meza JL, Rodriguez-Sierra JF, Aubert JP, Batra SK (2007) Human MUC4 mucin induces ultra-structural 
changes and tumorigenicity in pancreatic cancer cells. $\mathrm{Br} J$ Cancer 97: $345-357$

Nakajima M, Sawada H, Yamada Y, Watanabe A, Tatsumi M, Yamashita J, Matsuda M, Sakaguchi T, Hirao T, Nakano H (1999) The prognostic significance of amplification and overexpression of c-met and c-erb B-2 in human gastric carcinomas. Cancer 85: 1894-1902

Nakamura T, Yao T, Niho Y, Tsuneyoshi M (1999) A clinicopathological study in young patients with gastric carcinoma. J Surg Oncol 71: 214-219

Park HU, Kim JW, Kim GE, Bae HI, Crawley SC, Yang SC, Gum Jr JR, Batra SK, Rousseau K, Swallow DM, Sleisenger MH, Kim YS (2003) Aberrant expression of MUC3 and MUC4 membrane-associated mucins and sialyl $\mathrm{Le}(\mathrm{x})$ antigen in pancreatic intraepithelial neoplasia. Pancreas 26: e48 - e54

Reis CA, David L, Carvalho F, Mandel U, De BC, Mirgorodskaya E, Clausen $\mathrm{H}$, Sobrinho-Simoes M (2000) Immunohistochemical study of the expression of MUC6 mucin and co-expression of other secreted mucins (MUC5AC and MUC2) in human gastric carcinomas. J Histochem Cytochem 48: $377-388$

Reis CA, David L, Seixas M, Burchell J, Sobrinho-Simoes M (1998) Expression of fully and under-glycosylated forms of MUC1 mucin in gastric carcinoma. Int J Cancer 79: 402-410

Sakamoto H, Yonezawa S, Utsunomiya T, Tanaka S, Kim YS, Sato E (1997) Mucin antigen expression in gastric carcinomas of young and old adults. Hum Pathol 28: 1056-1065

Shibahara H, Tamada S, Higashi M, Goto M, Batra SK, Hollingsworth MA, Imai K, Yonezawa S (2004) MUC4 is a novel prognostic factor of intrahepatic cholangiocarcinoma-mass forming type. Hepatology 39: $220-229$

Singh AP, Chaturvedi P, Batra SK (2007) Emerging roles of MUC4 in cancer: a novel target for diagnosis and therapy. Cancer Res 67: 433-436

Singh AP, Moniaux N, Chauhan SC, Meza JL, Batra SK (2004) Inhibition of MUC4 expression suppresses pancreatic tumor cell growth and metastasis. Cancer Res 64: 622-630

Sommers CL (1996) The role of cadherin-mediated adhesion in breast cancer. J Mammary Gland Biol Neoplasia 1: 219-229
Springer GF, Desai PR, Ghazizadeh M, Tegtmeyer H (1995) T/Tn pancarcinoma autoantigens: fundamental, diagnostic, and prognostic aspects. Cancer Detect Prev 19: $173-182$

Swartz MJ, Batra SK, Varshney GC, Hollingsworth MA, Yeo CJ, Cameron JL, Wilentz RE, Hruban RH, Argani P (2002) MUC4 expression increases progressively in pancreatic intraepithelial neoplasia. Am J Clin Pathol 117: $791-796$

Tanaka M, Kitajima Y, Sato S, Miyazaki K (2003) Combined evaluation of mucin antigen and E-cadherin expression may help select patients with gastric cancer suitable for minimally invasive therapy. Br J Surg 90: 95- 101

Tasman-Jones C (1985) Gastric mucus-physical properties in cytoprotection. Med J Aust 142: S5-S6

Truant S, Bruyneel E, Gouyer V, De WO, Pruvot FR, Mareel M, Huet G (2003) Requirement of both mucins and proteoglycans in cell-cell dissociation and invasiveness of colon carcinoma HT-29 cells. Int J Cancer 104: $683-694$

Utsunomiya T, Yonezawa S, Sakamoto H, Kitamura H, Hokita S, Aiko T, Tanaka S, Irimura T, Kim YS, Sato E (1998) Expression of MUC1 and MUC2 mucins in gastric carcinomas: its relationship with the prognosis of the patients. Clin Cancer Res 4: 2605-2614

Weed DT, Gomez-Fernandez C, Yasin M, Hamilton-Nelson K, Rodriguez M, Zhang J, Carraway KL (2004) MUC4 and ErbB2 expression in squamous cell carcinoma of the upper aerodigestive tract: correlation with clinical outcomes. Laryngoscope 114: 1-32

Yamaguchi H, Wyckoff J, Condeelis J (2005) Cell migration in tumors. Curr Opin Cell Biol 17: 559-564

Yin L, Li Y, Ren J, Kuwahara H, Kufe D (2003) Human MUC1 carcinoma antigen regulates intracellular oxidant levels and the apoptotic response to oxidative stress. J Biol Chem 278: $35458-35464$

Yokoyama A, Shi BH, Kawai T, Konishi H, Andoh R, Tachikawa H, Ihara S, Fukui Y (2007) Muc4 is required for activation of ErbB2 in signet ring carcinoma cell lines. Biochem Biophys Res Commun 355: $200-203$ 